\title{
DFT Study of Oxidation Reaction Paths for Ethanol Gasoline
}

\author{
Li Na*, Han Lu, Guo Xin, Tao Zhiping, Long Jun \\ SINOPEC Research Institute of Petroleum Processing, Beijing, China
}

\section{Email address:}

lina.ripp@sinopec.com ( $\mathrm{Li} \mathrm{Na})$

${ }^{*}$ Corresponding author

\section{To cite this article:}

Li Na, Han Lu, Guo Xin, Tao Zhiping, Long Jun. DFT Study of Oxidation Reaction Paths for Ethanol Gasoline. Journal of Energy and Natural Resources. Vol. 9, No. 1, 2020, pp. 39-43. doi: 10.11648/j.jenr.20200901.17

Received: February 17, 2020; Accepted: March 24, 2020; Published: March 26, 2020

\begin{abstract}
A DFT study of oxidation reaction for ethanol molecule and representative conventional molecule in gasoline was performed. At first, the homolytic dissociation energy of the different $\mathrm{C}-\mathrm{H}$ bond in ethanol and hydrocarbon molecules was calculated and the $\mathrm{C}-\mathrm{H}$ active sites most likely to be attacked by oxygen molecule were obtained. Then, the reaction barrier of oxidation initiation reaction for different molecules was compared to conclude that the barrier energy of ethanol molecule was lower than the conventional gasoline molecule. It was found that the lower energy gap between the HOMO orbital of ethanol molecule and the LUMO orbital of oxygen molecule was the driving force to the oxidation initiation reaction. In addition, the possible further reaction paths of ethanol free radical after dehydrogenation have also been investigated, which may generate acetaldehyde or acetic acid. The two reaction paths actually existed at the same time, though compared with the acetic acid steps, the reaction path was shorter for generating acetaldehyde. It was indicated that ethanol gasoline is more prone to oxidation than conventional gasoline, which leads to changes in its molecular composition and physical and chemical properties. We should pay attention to the oxidation stability of ethanol gasoline during its storage and use.
\end{abstract}

Keywords: Ethanol Gasoline, Oxidation Chain Radical Reaction, Molecular Simulation, DFT Method

\section{Introduction}

Due to the abundance of different carbon numbers and various types of hydrocarbon molecules in gasoline, gasoline possibly react with the oxygen during its storage in oil tank or use in the automobile engine. The formed oxidation products could continue to react to produce the so-called gum [1-4] which could stick on the contacted metal surfaces. It will affect the oil supply seriously, lead to incomplete combustion and increase tailpipe emissions [5-8]. Based on the study of oxidation mechanism of hydrocarbon, it is found that the oxidation of hydrocarbon molecules follows the free radical chain reaction mechanism, which contains chain initiation, chain propagation and chain termination. The literature [9] shows that the oxidation mechanism is as follows.

Chain initiation: $\mathrm{RH}+\mathrm{O}_{2} \rightarrow \mathrm{R} \bullet+\mathrm{HOO} \bullet$

Chain propagation: $\mathrm{R} \bullet+\mathrm{O}_{2} \rightarrow \mathrm{ROO} \bullet$

$\mathrm{ROO} \bullet+\mathrm{RH} \rightarrow \mathrm{ROOH}+\mathrm{R} \bullet$

$\mathrm{ROOH} \rightarrow \mathrm{RO} \bullet+\cdot \mathrm{OH}$
$\mathrm{RO} \bullet+\mathrm{RH} \rightarrow \mathrm{ROH}+\mathrm{R} \bullet$
$\bullet \mathrm{OH}+\mathrm{RH} \rightarrow \mathrm{H}_{2} \mathrm{O}+\mathrm{R} \bullet$

Chain termination: $\mathrm{R} \bullet+\cdot \mathrm{R} \rightarrow \mathrm{R}-\mathrm{R}$

$\mathrm{ROO} \bullet+\cdot \mathrm{OOR} \rightarrow \mathrm{ROOOOR}$

In order to make full use of the aged grain, fifteen ministries have issued a joint document to achieve nationwide coverage of ethanol gasoline by 2020. The effect of the introduction of ethanol molecules on the performance of gasoline needs to be further studied. From the perspective of molecular structure, the presence of oxygen atoms in ethanol molecules may cause changes in oxidation stability compared with conventional gasoline. Further research is needed to determine whether deterioration will occur.

The general study is mainly using the macroscopic test to find "bad molecules" in gasoline which could experience oxidation or even deterioration. As the free radical chain reaction would produce a large number of free radicals, it is difficult to obtain the thermodynamic or kinetic data for the reaction of free radicals by experimental measurements [10, 
11]. It could not explain the mechanism of reaction path and deterioration in detailed. In this work, molecular simulation technique was used to reveal the information of the molecular level.

The present work intends to study the difficulty of oxidation chain reaction of ethanol and traditional hydrocarbon molecules and what reaction paths will make for the following radical of the ethanol gasoline. For this purpose reaction barrier of chain initiation reactions has been calculated by density functional theory (DFT) calculation. In addition, various molecular parameters like energy of the frontier molecular orbitals (HOMO, the highest occupied molecular orbital and LUMO, the lowest unoccupied orbital) in energy optimized geometry were also analyzed. Furthermore, the specific reaction paths of the ethanol gasoline were investigated in detailed and the possible oxidation intermediates were given also with DFT methods.

\section{Computational Details and Models}

\subsection{Computational Details}

The computational results were performed with density functional theory (DFT) by $\mathrm{Dmol}^{3}$ module $[12,13]$ in the Material Studio 8.0 software developed by DaussaultBiovia Inc. Geometry optimizations and the corresponding property parameter calculation of all molecules were carried out with the generalized gradient approximation (GGA) together with Perdew-Burke-Ernzerhof (PBE) functional [14] of DFT employing basis set DNP. SCF calculations were converged tightly (SCF tolerance: $1 \times 10^{-6} \mathrm{Ha}$; energy: $1 \times 10^{-5} \mathrm{Ha}$; $\max$ force: $0.0002 \mathrm{Ha} / \mathrm{nm}$; $\max$ displacement: $5 \times 10^{-4} \mathrm{~nm}$ ). Transition state search protocol was chosen Complete LST/QST method.

\subsection{Model Compounds}

Gasoline is a volatile mixture of hydrocarbons composed of olefins, paraffins, naphthenes and aromatic hydrocarbons (C4 C12), whose boiling points is in the $30 \sim 220^{\circ} \mathrm{C}$ range.

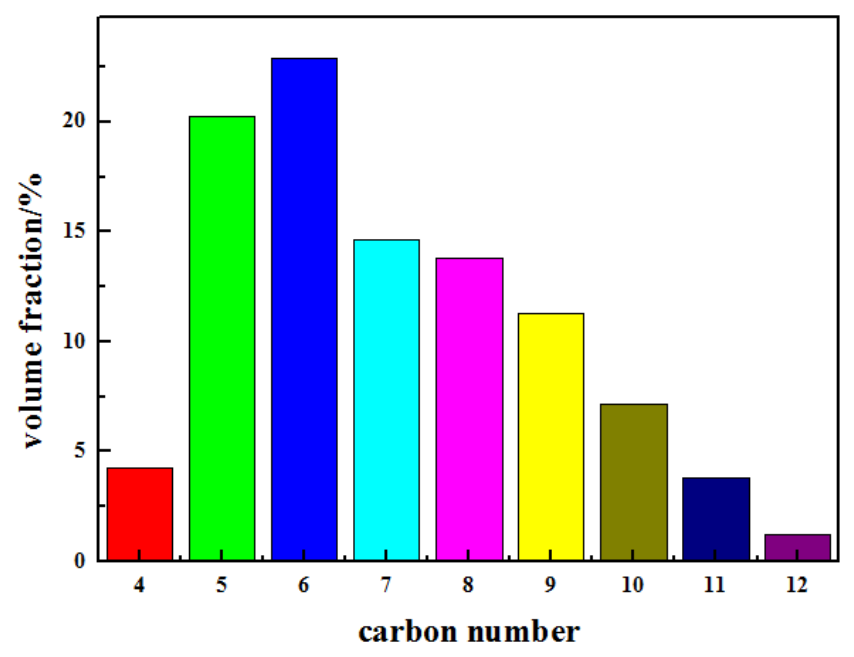

Figure 1. Carbon number distribution in gasoline pool.
The carbon number distribution of main components in gasoline pool was analyzed, as shown in figure 1. It can be seen from that C6 is the component with the highest content. In this work, hexane was selected as traditional gasoline model compound, to study the differences in properties, such as oxidation and adsorption behavior, between ethanol molecules and regular gasoline molecules, whose structure was shown in Figure 2.

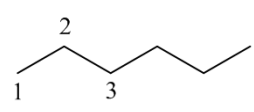

(a) Hexane

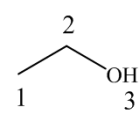

(b) Ethanol
Figure 2. Structure of model compounds in ethanol gasoline.

\section{Results and Discussion}

There are active sites easily be oxidized in hydrocarbon or ethanol molecules in ethanol gasoline. And the reaction path follows the chain free radical mechanism. which contains chain initiation, propagation and termination. Here we study the oxidation chain radical reaction mechanism of gasoline molecule and ethanol molecule to compare the difference of oxidation performance between ethanol molecule and traditional gasoline molecule.

\subsection{Oxidation Chain Initiation}

Because of the presence of oxygen in the air, then contacting with the molecules, the ethanol gasoline molecules were attacked by oxygen molecules, which was the oxidation chain initiation step. Due to the steric hindrance, not the $\mathrm{C}-\mathrm{C}$ bond but the $\mathrm{C}-\mathrm{H}$ bond would be attacked by the oxygen molecules. Then it can generate free radicals $\mathrm{R} \bullet$ and hydrogen peroxide free radicals $\mathrm{HOO} \bullet$, as shown below: $\mathrm{RH}+\mathrm{O}_{2} \rightarrow \mathrm{R} \bullet+\mathrm{HOO} \bullet$. In this work, $\mathrm{R}$ refers to hexane or ethanol. The dehydrogenated reaction was happened.

In this hydrogen transfer reaction, the dissociation energy of $\mathrm{C}-\mathrm{H}$ bond determine which site of $\mathrm{C}-\mathrm{H}$ was most likely to be attacked by oxygen molecules. The site with the minimum homolytic dissociation energy is the most vulnerable to be attacked. As shown in Table 1, the homolytic dissociation energy of the $\mathrm{C}-\mathrm{H}$ bond in different position of two compounds was calculated. It can be seen the $\mathrm{C}-\mathrm{H}$ bonds in the two compounds most likely to be attacked by oxygen respectively were both $\mathrm{C}-\mathrm{H}(2)$. The results indicated that, for hexane molecule, compared with the $\mathrm{C}-\mathrm{H}$ bond in primary carbon position, the homolytic dissociation energy of the $\mathrm{C}-\mathrm{H}$ bond in the secondary carbon position is lower, and which connecting with methyl groups is the lowest. For the ethanol molecule, the homolytic dissociation energy of the $\mathrm{C}-\mathrm{H}$ bond in the $\alpha$ position of $\mathrm{O}-\mathrm{H}$ bond is the lowest due to the electron attraction of $\mathrm{O}-\mathrm{H}$ bond. It's about $110 \mathrm{~kJ} / \mathrm{mol}$ lower than that of gasoline molecule, which was indicated that this $\mathrm{C}-\mathrm{H}$ bond in ethanol molecule was more likely to be dehydrogenized to generate radicals. 
Table 1. Homolytic dissociation energy of $\mathrm{C}-\mathrm{H}$ bond in model compounds (Unit: $\mathrm{kJ} / \mathrm{mol}$ ).

\begin{tabular}{lll}
\hline C-H & Gasoline & Ethanol \\
\hline 1 & 551.13 & 455.38 \\
2 & 519.32 & 405.64 \\
3 & 520.93 & 440.87 \\
\hline
\end{tabular}

In above calculation, the $\mathrm{C}-\mathrm{H}$ active site which was most likely to be attacked by oxygen molecules was obtained. Then transition state search was performed for the two reactions. The structures of reactants, transition states and products are shown in Table 2. It can be seen from the table, the mechanism of the initiation reaction for the conventional gasoline molecule or ethanol molecule were the same reaction path, which both generated a carbon radical site and a peroxy radical.

Table 2. Reaction structure in initiation reaction.

Structure

In addition, the reaction energy barrier of oxidation initiation reaction for gasoline hydrocarbon molecule or ethanol was calculated. $\mathrm{E}_{\mathrm{a} \text { (gasoline) }}=425.06 \mathrm{~kJ} / \mathrm{mol}$ and $\mathrm{E}_{\mathrm{a}(\text { ethanol })}=156.33 \mathrm{~kJ} / \mathrm{mol}$. The reaction energy barrier of gasoline hydrocarbon was too high to initiate the oxidation reaction. Compared with the gasoline molecules, the chain initiation reaction barrier of ethanol is much lower, which illustrated the traditional gasoline molecules especially alkane could not be oxidized, while ethanol molecule are easy to oxidize, which leads to the oxidation was more likely happen for ethanol molecules contributing the deterioration of ethanol gasoline and changes in physical and chemical properties.

Based on the frontier orbital theory, for a two-molecules reaction, when the frontier orbitals are symmetry adapted, LUMO orbital energy level of reactant A (or B) and HOMO orbital energy level of reactant B (or A) more closely, the electron transfer reaction is more likely to happen, thus the reaction happens. Here the oxygen molecule obtains electrons because of its higher electronegativity. And ethanol gasoline molecules donate electrons. Therefore, LUMO orbital of oxygen molecule and HOMO orbitals of gasoline molecules was further analyzed. The results were shown in figure 3 and figure 4 . It can be seen the LUMO orbital of oxygen molecule and the HOMO orbitals of ethanol gasoline molecules are all symmetry adapted.

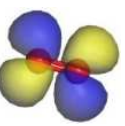

Figure 3. LUMO orbital of oxygen molecule.

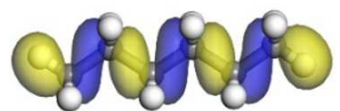

(a) gasoline

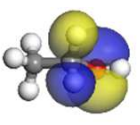

(b) ethanol

Figure 4. HOMO orbitals of ethanol gasoline molecules.

The calculated energy level of LUMO orbital of oxygen molecule is $-4.596 \mathrm{eV}$, which of the HOMO orbital of gasoline and ethanol molecules is $-6.828 \mathrm{eV}$ and $-6.016 \mathrm{eV}$ respectively. The energy level gap between HOMO orbital of ethanol molecule and the LUMO orbital of oxygen is much less than that of HOMO orbital of conventional gasoline molecule and LUMO orbital of oxygen molecule. In contrast, it can tell that electrons in HOMO orbital of the ethanol molecule was much easier to transfer into the LUMO orbital of the oxygen molecule. This is the basic driving force to
\end{abstract} oxidation reaction for ethanol gasoline.

\subsection{Oxidation Chain Propagation}

After chain initiation reaction, ethanol molecules dehydrogenate attacked by oxygen to form corresponding free radicals. Due to the presence of single electron that has not yet formed bonds, this free radical site was easily attacked by oxygen molecules, resulting in generation of peroxide free radicals, shown in figure 5. The literature [11] shows that the reaction energy barrier of this step is close to zero, which is very easy to happen. The radical site was attacked by oxygen and produced a peroxide radical. Because of the peroxy bond, the radical has strong oxidation ability, even more than oxygen.

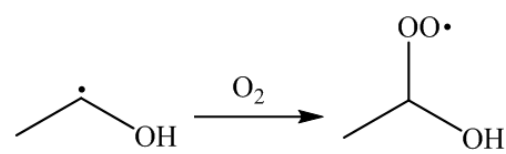

Figure 5. The next reaction step for the ethanol radical.

So in the next reaction path, the free radical will continue to attack other sites where it can take electrons to form new chemical bond. Now, due to the almost zero reaction energy barrier, we believe that there are already a large number of peroxy radicals in the present system, which can attack the surrounding ethanol molecules or other hydrocarbon molecules and produce peroxides. The reaction path was shown in figure 6.

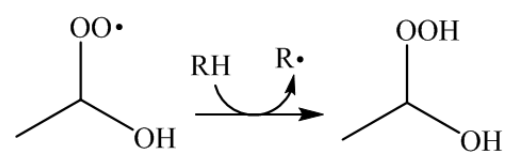

Figure 6. The next reaction step for the peroxy radical.

As two oxygen-containing functional groups are connected to $\alpha-\mathrm{C}$ atom in the intermediate, just because of their electron 
binding effect, the dissociation energy of the $\mathrm{C}-\mathrm{H}$ bond at this position will be so weak that it is likely to provide electrons and make dehydrogenation reaction. As the hydroxyl group itself has strong oxidizing ability, the hydroxyl groups in the peroxy bond and the alcoholic structure both could grab the hydrogen atom which the corresponding carbon is attached to. The reaction steps were listed in figure 7 . But which path would happen more likely should make further discussion. Based on the principle that the less energy a structure has, the easier it is to generate. Which path exactly should depend on the stability of the corresponding product. while the alcohol hydroxyl attacks the hydrogen atom, it will form a carbon radical site with lone pair electrons, which is so unstable that cannot exist for time. This reaction step could not carry out in fact. When the hydrogen transfer occurs to the hydroxyl group in the peroxy bond, the carboxyl functional group formed, that is, the acetic acid, which is naturally occurring stable structure. Under certain temperature conditions, the acetic acid structure can survive for a period of time, but with the harsh engine conditions, the temperature increases, the acetic acid molecules can continue to dehydrogenate, and even $\mathrm{C}-\mathrm{C}$ bond dissociation could occur, producing smaller fragments.

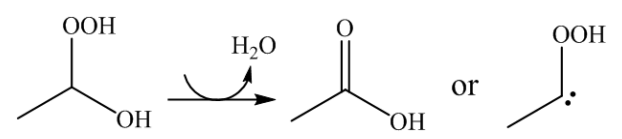

Figure 7. The next reaction step for the peroxide.

There's another path that's worth considering which is continuous dehydrogenation. As shown in figure 8 , based on the homolytic dissociation energy results in table 1 , the $\mathrm{C}-\mathrm{H}$ bond in hydroxyl group could also be dehydrogenated by oxygen to produce radical site. Then the two single electrons will form a new bond. Thus the carbonyl structure of acetaldehyde appeared [15].

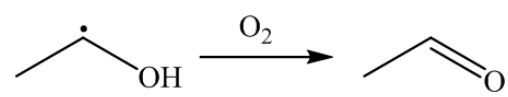

Figure 8. The other reaction path for the ethanol radical.

Compared with the acetic acid steps, the reaction path was shorter for generating acetaldehyde, though the barrier of the first few steps of the acetic acid steps was lower theoretically. In fact, these two reaction paths are both going to happen, and the two products are existing in the system at the same time.

It can be seen the ethanol molecules are probably oxidized into acetic acid or acetaldehyde, which were more oxidized and have higher oxygen content. The generation of acetic acid will lead to the strong acidity of ethanol gasoline, which will have a certain degree of influence on engine fuel tank, oil and gas pipeline, storage tank, gas station refueling gun and other materials.

Through the above research, the oxidation stability of ethanol gasoline is worse than that of conventional gasoline. During storage and use of ethanol gasoline, measures such as avoiding exposure to air or adding antioxidant, should be taken. In terms of physical and chemical parameters, we should pay special attention to the induction period of ethanol gasoline and the content of oxidized gum.

\section{Conclusion}

Using molecular simulation technology based on DFT methods, the oxidation reaction including chain initiation, propagation of conventional gasoline molecule and ethanol molecule attacked by oxygen was investigated. According to the reaction barrier values, the oxidation of ethanol molecule was more easily to be initiated. The LUMO or HOMO orbitals and their energy levels of the optimized oxygen molecule and ethanol gasoline molecules were calculated. It can be seen that the ethanol molecule with lower absolute values of the energy gap made electron transfer more easily. In addition, the different chain propagation reaction paths were revealed in detailed producing oxidation intermediates such as acetaldehyde or acetic acid, which would contribute to deterioration of ethanol gasoline.

\section{Acknowledgements}

The first author Li Na thanks the DaussaultBiovia Inc. for their technical expertise and commitment to this project.

\section{References}

[1] Nagpal JM, Joshi GC, Singh J, Kumar K. Studies on the nature of gum formed in cracked naphtas [J]. Oxid Commun 1998, 21 (4): 468-477.

[2] Xue Dong, Yachao Chang, Bo Niu, et al. Development of a practical reaction model of polycyclic aromatic hydrocarbon (PAH) formation and oxidation for diesel surrogate fuel [J]. Fuel, 2020, 267: 117159.

[3] Kinoshita M, Saito A, Matsushita S, Shibata H, Niwa Y. Study of deposit formation mechanism on gasoline injection nozzle [C]. SAE paper 1998, 19: 355-357.

[4] Li Na, Long Jun, Zhao Yi, et al. Molecular Simulation of the Mechanism of Oxidation Gum Formation of Typical Gasoline Hydrocarbon [J]. Acta Petrolei Sinica (Petroleum Processing Section), 2018, 34 (2): 354-364.

[5] Li Na, Long Jun, Zhao Yi, Tao Zhiping, Dai Zhenyu. DFT study of oxidation initiation for different compound in gasoline [J]. Journal of Clean Energy Technologies, 2017, 6 (3): $242-245$.

[6] Paul Lacey, Sandro Gail, Jean Marc Kientz, et al. Internal Fuel Injector Deposits [C]. SAE Paper 2011-01-1925.

[7] Akio Tanaka, Koichi Yamada, Toshihiko Omori, et al. Inner Diesel Injector Deposit Formation Mechanism [C]. SAE Paper, 2013-01-2661.

[8] Ji Xiang, Song Yingjin, Liu Rui, et al. Effect of oxidation decay of alcohol fuel engine on exhaust emission [J]. Journal of Harbin University of Commerce (Natural Sciences Edition), 2018, 34 (5): 573-576. 
[9] Nicholas J. Kuprowicz, Steven Zabarnick, Zachary J. West, et al. Use of Measured Species Class Concentrations with Chemical Kinetic Modeling for the Prediction of Autoxidation and Deposition of Jet Fuels [J]. Energy \& Fuels 2007, 21, 530-544.

[10] Ruben Epping, Stefanie Kerkering, Jan T. Andersson. Influence of Different Compound Classes on the Formation of Sediments in Fossil Fuels During Aging [J]. energy\& fuels, 2014, 28: 5649-5656.

[11] Zheng Guiling. Influence of compounds containing nitrogen, sulfur and oxygen on the oxidation stability of oil [D]. Beijing, China University of Petroleum, 2018.
[12] Delley B. From molecules to solids with the $\mathrm{DMol}^{3}$ approach [J]. J Chem Phys, 2000, 113 (18): 7756-7764.

[13] Kohn W, Sham L J. Self-consistent equations including exchange and correlation effects [J]. Phys Rev, 1965, 140 (4A): A1133-A1138.

[14] J. P. Perdew, K. Burke, M. Ernzerhof, Generalized gradient approximation made simple, Phys. Rev. Lett. 1996, 77: 3865-3868.

[15] Kamlesh Kumar, Prashant Kumar, Penny Joshi, et al. IBX-TfOH mediated oxidation of alcohols to aldehydes and ketones under mild reaction conditions [J]. Tetrahedron Letters, 2020, 2: 151749. 